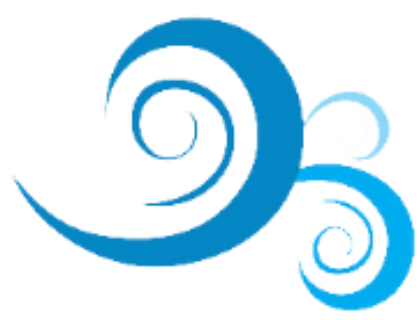

\title{
INTERSECCIONALIDADE E COLONIALIDADE COMO CHAVES INTERPRETATIVAS: REFLEXÕES AMAZÔNICAS SOBRE DIREITOS HUMANOS
}

IGOR VELOSO RIBEIRO

Mestre em Direitos Humanos e Desenvolvimento da Justiça (DHJUS/Emeron/Unir), Procurador do Estado de Rondônia (PGE-RO), Porto Velho (RO), Brasil

ORCID: https://orcid.org/0000-0003-0687-8650

igorvelosor@gmail.com

ESTEVÃO RAFAEL FERNANDES

Doutor em Estudos Comparados sobre as Américas (UnB) Professor Adjunto da Universidade Federal de Rondônia (Unir), Porto Velho (RO), Brasil ORCID: http://orcid.org/0000-0002-1667-0549 estevaofernandes@gmail.com

\begin{abstract}
RESUMO: Buscando responder à questão "a interseccionalidade é uma opção decolonial?" refletimos, de modo crítico, sobre a adequação dessas duas chaves interpretativas para a compreensão dos Direitos Humanos em povos das Américas. A teoria da interseccionalidade propõe uma análise dos entrecruzamentos dos marcadores sociais gênero/raça/classe. Por outro lado, decolonialidade apresenta um contexto histórico, político e social, a partir do qual compreende-se feixes hierárquicos como heranças coloniais. Essas chaves interpretativas trazem, em suas reflexões, formas de compreender a violação seletiva de direitos humanos e desconstruir os sistemas de hierarquização e poder. Buscamos aqui apontar suas limitações e potencialidades nesse sentido.
\end{abstract}

PALAVRAS-CHAVE: Interseccionalidade; Direitos Humanos; Decolonialidade.

\section{INTERSECTIONALITY AND COLONIALITY AS INTERPRETIVE KEYS THINKING HUMAN RIGHTS FROM THE AMAZON}

\begin{abstract}
This article starts from the question: "is intersectionality a decolonial option?" to critically reflect on the adequacy of these two interpretative keys to the understanding of Human Rights in peoples of the Americas. The intersectionality theory proposes an analysis of the intercrossing of social markers of gender/race/class. On the other hand, decoloniality presents a historical, political and social context, from which one understands hierarchical beams as colonial inheritances. These interpretive keys bring, in their reflections, ways to understand the selective breach of human rights and deconstruct the systems of hierarchy and power. In this sense, we seek here to point out their limitations and potential.
\end{abstract}

KEY WORDS: Intersectionality; Human rights; Decoloniality.

\section{INTERSECCIONALIDAD Y COLONIALIDAD COMO CLAVES DE INTERPRETACIÓN: REFLEXIONES AMAZÓNICAS SOBRE LOS DERECHOS HUMANOS}

RESUMEN: Buscando responder a la pregunta "¿es la interseccionalidad una opción descolonial?" reflexionamos críticamente sobre la idoneidad de estas dos claves interpretativas para entender los 
derechos humanos en los pueblos de las Américas. La teoría de la interseccionalidad propone un análisis de las intersecciones de los marcadores sociales de género/raza/clase. Por otro lado, la descolonialidad presenta un contexto histórico, político y social, a partir del cual las vigas jerárquicas se entienden como legados coloniales. Estas claves interpretativas aportan en sus reflexiones formas de entender la violación selectiva de los derechos humanos y de deconstruir los sistemas de jerarquización y de poder. Buscamos aquí para señalar sus limitaciones y potencialidades en este sentido.

PALABRAS CLAVE: Interseccionalidad; Derechos Humanos; Descolonialidad.

\section{INTRODUÇÃO}

A ideia para este artigo partiu de uma pergunta aparentemente banal, feita em uma mesa da qual os autores participaram, em um Congresso sobre Direitos Humanos em Porto Velho, Rondônia. A questão, realizada de modo genérico para os integrantes que compunham a mesa de debates era se "a interseccionalidade seria uma opção decolonial". A resposta dada pela principal oradora daquela mesa - um "sim", quase imediato - nos incomodou, na melhor acepção da palavra.

Temos aí duas palavras cada vez mais utilizadas em círculos fora dos grandes centros produtores de ciências humanas no país, sobretudo em Universidades e Movimentos Sociais do eixo norte-nordeste, e/ou relacionadas a demandas negras, indígenas e quilombolas. Pensamos que, de certa forma (aliás, de inúmeras formas), pensar de forma mais ponderada essa questão, tão despretensiosamente feita em um Congresso poderia ir ao encontro da chamada deste Dossiê, mesmo sem tratar de um texto feito a partir do estudo de um caso empírico - ao menos não diretamente.

O ponto aqui é: conceitos ou chaves interpretativas como a interseccionalidade e a colonialidade bastam? Se buscarmos pensar um contexto estrutural mais amplo a partir do qual Direitos são cada vez mais ameaçados, uma relação entre essas perspectivas é algo producente ou, ao contrário, encapsula nossa realidade social em uma nota de rodapé de teorias produzidas alhures, mesmo que em contextos de luta? O que propomos aqui, em um movimento mais radical, é não apenas buscar correlacionar essas duas chaves - interseccionalidade e colonialidade - mas, sobretudo, superá-las.

Evidentemente ambas são interpretações poderosíssimas da realidade social e põem em xeque uma distribuição de poderes, saberes e subjetividades vistas como norma[i]s. O branco, heterossexual, cisgênero, centro-sulista, urbano etc. é visto como default e tais perspectivas buscam evidenciar e contrapor isso. No entanto, elas 
possuem limitações e se nos impõem desafios, especialmente no sentido de propormos epistemopolíticas ainda mais radicais, que se contraponham, a contento, à guinada também radical à direita no continente $e$, mais recentemente - e perigosamente - no Brasil. Como, de certa forma, propomos aqui uma agenda mais ampla para estudos relacionados à Direitos Humanos em contextos fora do equivalente latino-americano ao WASP (acrônimo que em inglês significa "Branco, Anglo-Saxão e Protestante", epítome do "americano padrão"), mas não restrita a esses Direitos, este artigo terá uma estrutura relativamente escolar, apresentando em primeiro lugar do que falamos ao falarmos em interseccionalidade e colonialidade, buscando relacioná-las para, em seguida, propor algumas possibilidades de rupturas.

Assim, tratamos sobre a abordagem interseccional dos marcadores sociais proposta no final do século $\mathrm{XX}$ e debatida até os dias de hoje, suas limitações e os entraves que sua aplicação eventualmente encontra no campo prático. Em princípio, quando visualizada como método de análise de discriminações e opressões vivenciadas por determinados grupos, uma perspectiva interseccional funciona. Entretanto, ao negar a origem histórica, política e social das estruturas de poder que legitimam atitudes desumanizantes contra sujeitos que fogem à cis/heteronormatividade euronorcêntrica, a interseccionalidade não encontra uma solução lógica ao problema da violação seletiva de Direitos Humanos, especialmente quando se considera o caldeirão pluricultural latino-americano - incluindo nós, da pindorama brasílica, em especial em terras amazônicas e periféricas.

A Amazônia tem entrado cada vez mais na pauta, no Brasil e no mundo. Neste exato momento em que nós, que revisamos este texto - aliás, registramos os sinceros agradecimentos aos valiosíssimos comentários dos pareceristas da Monções - vemos Joe Biden ser eleito o quadragésimo sexto presidente dos Estados Unidos. Um dos elementos que a imprensa mais tem destacado é, justamente, a mudança de paradigma do próximo governo norte-americano em relação ao meio ambiente, e à Amazônia, especificamente. Tanto os posicionamentos de Biden quanto de sua vice, Kamala Harris, tem sido indicações de que a política ambiental brasileira, caso o governo brasileiro mantenha laços programáticos tão estreitos com aquele país, deverão rever sua postura com relação a esta região do país. Da mesma forma, nosso vice-presidente, Hamilton Mourão, visita o norte amazônico com um entourage formado por embaixadores, a fim de mostrar como o Brasil, apesar de todos os 
indicadores possíveis apontarem o contrário, é um exemplo internacional de respeito ao ambiente e aos povos amazônicos. Também na pauta, hoje, temos um apagão de mais de doze dias em praticamente todo o estado do Amapá. Nas redes sociais, a população amapaense clama por visibilidade em um momento crítico de falta de água, alimentação, dinheiro físico, segurança etc.

Três olhares para a Amazônia, distintos em abordagem e atores envolvidos, chamando a atenção para elementos distintos a partir de sua importância geopolítica (local, nacional e mundial), ambiental, de sua diferença identitária humana e, paradoxalmente, de sua invisibilidade e precariedade em termos de infraestrutura e atendimento de necessidades básicas.

Fato é que essas várias "Amazônias" confluem, justamente, para essa questão: somos um paradoxo. Os olhares distantes nos enxergam como um grande celeiro de oportunidades por conta de nossa biodiversidade e/ou capacidade de criação energética; de um espaço a ser explorado com commodities (sobretudo soja); da manutenção da imagem moldada ainda em tempos de ditadura militar - uma terra sem homens - ou, da mesma forma, um risco potencial e uma tentação para "potências estrangeiras" implantarem uma suposta "agenda globalista" por meio de "organizações internacionais"... Uma terra rica com gente pobre, um "inferno" verde, um paraíso inexplorado: visões que, na prática, pouco ou nada tem a ver com viver aqui, de fato.

Em que pese serem, essas "Amazônias", marcadas pelos paradoxos indicados acima - fruto de séculos de colonização predatória e de políticas mal geridas - a maior marca, desta região, é sua diversidade humana e as formas de ser/viver/pensar/estar-[n]o mundo absolutamente plural. E é isso que este texto tenta, em parte, explorar: as possibilidades de chaves interpretativas gestadas em outros contextos e com outras possibilidades, alcançarem plenamente êxito na compreensão de fenômenos advindos diretamente da colonização. Fica o alerta, desde já, que embora este texto parta da Amazônia, ele não se restringe a elas. Ao contrário, é fruto do tipo de angústias que nos movem o pensamento, enquanto ação transformadora.

Assim, compreender estratégias de dominação aplicadas às relações sociais estabelecidas desde a lógica da colonialidade partindo de dicotomias como homem/mulher, colonizador/colonizado, cristão/não-cristão, heterossexual/LGBTQI+, cisgênero/transgênero, nos leva a entender padrões de violação seletiva de Direitos 
Humanos e, como mostraremos, a interseccionalidade não alcança de forma satisfatória os fundamentos necessários à percepção da estereotipização de sujeitos de acordo com a retórica da modernidade. Diante disso, abordamos as eventuais limitações de uma visada interseccional na efetivação de políticas voltadas à desconstrução das estruturas de poder que oprimem e discriminam sujeitos naturalmente distantes do padrão normalizado.

\section{INTERSECCIONALIDADE: BUSCANDO UMA DEFINIÇÃO}

Dito de forma breve, a interseccionalidade é um conceito de cunho sociológico que se dedica ao estudo das sobreposições ou intersecções entre os marcadores sociais derivados das diversas estruturas de poder existentes na sociedade. Essas estruturas de poder estabelecem sistemas de opressão, dominação ou discriminação e, nessa teoria, o combate a cada um desses fenômenos é estudado em conjunto com as demais opressões impostas sobre determinado indivíduo.

A origem do estudo da interseccionalidade remonta ao movimento conhecido como black feminism, que ganhou voz na década de 1970, ao criticar radicalmente o feminismo branco, exercido por mulheres de classe média de maioria cis/heteronormativa. As black feminists elaboraram estratégias para combater todas as formas de opressão intramovimento, o que, até certo ponto, encontra o conceito de interseccionalidade descrito por Kimberlé Williams Crenshaw anos mais tarde.

Para se compreender a conexão entre o movimento black feminism e a ideia contemporânea de interseccionalidade, é importante ter em mente sua origem como uma resposta a outros movimentos, os quais, embora comportassem convicções antidiscriminatórias, não ofereciam um espaço amistoso às mulheres negras, sexualmente oprimidas nos movimentos de libertação negra da época e racialmente oprimidas nos movimentos feministas. Esse contexto é, ele mesmo, representativo da ideia de sobreposição de marcadores sociais, utilizado no âmbito do pensamento interseccional.

O termo "interseccionalidade", entretanto, somente foi utilizado no ano de 1989, quando Crenshaw escreve o ensaio "Demarginalizing the Intersection of Race and Sex: A Black Feminist Critique of Antidiscrimination Doctrine, Feminist Theory and Antiracist Politics". A ideia expressa pelo termo não era nova, como afirma a autora 
(CRENSHAW, 2015), mas a utilização do vocábulo organizou a noção de interdependência existente entre as relações de poder atinentes à raça, gênero e classe social, bem como as consequências da cumulação de diferentes formas de subordinação em um determinado indivíduo. Desse modo, ela cria uma imagem de diversas avenidas, cada qual representando o fluxo de determinada opressão. Quando duas ou mais dessas avenidas se cruzam, a mulher necessita enfrentar as opressões dos fluxos que atuam de forma convergente sobre ela.

As violações de direitos humanos exemplificadas por Kimberlé Crenshaw evidenciam casos de estupros por motivos étnicos, como no caso das mulheres de Ruanda e da Bósnia, cuja imagem era frequentemente associada à promiscuidade $e$ à uma abertura sexual maior que a de outras mulheres, razão pela qual a sociedade legitima agressões sexuais às quais são submetidas. Como a autora destaca, isso se daria pela ideia de que raça determine os padrões sexuais e comportamentais das pessoas (CRENSHAW, 2004).

De acordo com a teoria de Crenshaw, essa vulnerabilidade da mulher nãobranca, reforçada pela propagação de estereótipos físicos e sexuais, evidencia a marginalização dessas mulheres dentro dos discursos antirracistas. Dessa maneira, a discriminação contra mulheres não-brancas não se enquadra no campo da discriminação racial, de gênero ou social, tratando-se de uma discriminação interseccional, por meio da qual a mulher é obrigada a suportar as consequências de cada sistema de opressão ao qual é submetida (CRENSHAW, 2004).

$O$ pensamento de Crenshaw pode ser entendido como uma perspectiva sistêmica porque enfatiza as consequências da hierarquização social sobre as identidades, sendo estas efeito determinante daquela. Nessa senda, a autora desconsidera a condição relacional de gênero/raça/classe como categorias analíticas. Segundo Baukje Prins (2006), a interseccionalidade crenshawniana ao revelar apenas as estruturas de dominação, suas representações sociais; e, efeitos materiais e simbólicos para os grupos subalternos, subestima as habilidades criativas e estratégicas de ação. Ainda em Prins (2006), como uma alternativa para a visão sistêmica de interseccionalidade, surgiu uma abordagem construtivista feminista anglófona que adota um ponto de vista de autoridade mais dinâmico e relacional a partir das contribuições gramscianas, assim, os processos pelos quais os indivíduos tornam-se sujeitos não se resumem apenas a estar subalternizado a um poder 
soberano ou "sistema", mas implica um tonar-se um sujeito que mobiliza transformação das formas limitativas de categorização por meio da sua trajetória de vida e de recursos capacitadores. Nesse sentido, a ideia de agência confere coerência à interseccionalidade.

A teórica de estudos culturais estadunidenses Anne Mcklintock (1995), ao trabalhar os efeitos do imperialismo, compreende que as categorias gênero/raça/classe não existem de forma estanque, outrossim, propõe categorias intimamente articuladas, recíprocas e contraditórias. Segundo Mcklintock (1995), são nas contradições dos entrecruzamentos das categorias de articulação que reside a possibilidade de entabular resistências à coerção por movimentos de agência consubstanciados na permissão, refuta, engajamento e distensão.

Para Avtar Brah (2006), outra pensadora que rechaça a superposição sistêmica crenshawniana, faz-se necessário estudar os diferentes fatores de opressão em conjunto, uma vez que estes fatores estabelecem uma relação entre si. A autora defende que a interseccionalidade não deve ser analisada de um ponto de vista de gênero, como dispõe Crenshaw, mas partindo de um enfoque nas diferenças presentes de forma subjetiva nas relações sociais, nas experiências, vivências e na identidade dos sujeitos. Segundo Brah (2006), as diferenças podem ser apresentadas em marcadores de hierarquia e opressão, como o racismo, por exemplo, ou como diversidade e democracia.

Na perspectiva de Adriana Piscitelli (2008), o trabalho de Avtar Brah (2006) ao propor uma análise panorâmica e simultânea da subjetividade e identidade para alcançar as forças da autoridade nos sistemas de diferenciação social, aproxima-se do que foi produzidos pelas feministas pós-coloniais terceiro-mundistas porque orientadas epistemopoliticamente às compreensões da subjetividades como produto de um processo social atravessado pelo regime colonial-capitalístico, noutras palavras, histórico e geograficamente localizado.

Foi nesse contexto que a discussão sobre interseccionalidade chegou ao Brasil, principalmente graças à Lélia Gonzalez (falecida em 1994), que dedicou boa parte da sua vida à pesquisa das relações entre classe, raça e gênero, particularmente na vivência social da mulher negra, por meio de uma abordagem de cunho cultural, criticando o pensamento social brasileiro e a cultura nacional que fortalece o sistema de opressões (RIOS; RATTS, 2018). Na medida em que Gonzalez analisava e 
percebia as divisões das categorias de análise em raça, sexo e classe, dos fenômenos sociais de opressão e discriminação em racismo, sexismo e segregação, e a articulação entre diferentes movimentos sociais, chegava à conclusão de que a mulher negra sofre discriminação advinda de três eixos distintos e, por via de consequência, seu lugar de trabalho também é discriminado, criando estereótipos como as figuras da "mulata" e da "doméstica" (GONZALES, 1984).

Essa autora acreditava ser o feminismo no Brasil uma luta de mulheres brancas de classe média desejosas pela emancipação social e a inserção no mercado de trabalho, e, com isso, sobrava às mulheres negras e pobres posições de trabalho doméstico, com salários baixos e quase nenhuma garantia trabalhista. O movimento feminista não alcançava a luta das mulheres negras, inclusive atuando na legitimação de sua segregação - em um exercício de pensamento em muito semelhante às ideias de Crenshaw.

Nos estudos feministas, o Brasil é um dos países latino-americano pioneiros. Numa larga medida, o movimento feminista tupiniquim não foi marcado pela radicalidade encontrada nos ativismos feministas do Norte-Global. Aqui, a partir da década de 1970, desenvolveu-se um feminismo que desafiou o regime militar, orientado politicamente à esquerda, porém relativamente moderado em termos de contestação do status quo masculino. Desde então, tais estudos foram marcados pela interdisciplinaridade e abordagens pós-coloniais que, por sua vez, contribuíram com uma visada mais atenta às particularidades e interações relacionais de poder entre gênero, raça, sexualidade, etnicidade, nacionalidade, levando em conta também aspectos políticos e seus efeitos nas subjetividades (PISCITELLI, 2013).

Mais recentemente, Adriana Piscitelli (2008) propôs o estudo das categorias de articulação (McKLINTOCK, 1995), quais sejam, classe, gênero e raça, em conjunto, no intuito de se compreender efetivamente a lógica e as consequências políticas de subordinações para além de dois sistemas de marcadores específicos como sexo e gênero ou raça e gênero. Nesse sentido, essa autora dedicou-se à análise de diferentes modelos de intersecção - como entre nacionalidade, gênero e sexualidade - ao falar sobre a sexualização e racialização das mulheres brasileiras migrantes. Seus achados sugerem que tais articulações redundam num racismo etnicizado com intensidades distintas entre as mulheres latino-americanas, negras e indígenas no contexto do sul europeu. 
Como se vê, a interseccionalidade é um conceito teórico, construído com base nas lutas contra sistemas de opressão política e culturalmente arraigados nas sociedades pelo mundo e, conforme afirma Crenshaw (2004), serve como uma ponte entre questões de gênero, raça e classe nos discursos acerca dos direitos humanos. Entrementes, interessa gizar que as diferentes formas e arranjos que categorias analíticas como classe, raça, gênero (aqui inclusas as dissidências e expressões múltiplas), sexualidade, etnicidade, regionalidade, nacionalidade etc., interagem nas configurações de identidade/diferença, interpelação/posição de sujeito/subjetividade, assimetria e privilégios, atualmente lidas como interseccionalidade, não são tão recentes e se sujeitam a diferentes perspectivas de raciocínio.

Evidentemente não é nosso interesse aqui esgotar a extensa literatura sobre esse conjunto teórico, mas o de apresentar, em linhas gerais, algumas de suas proposições e pressupostos a fim que possamos traçar, como faremos a seguir, algumas considerações de cunho mais reflexivo sobre alguns de seus limites.

\section{INTERSECCIONALIDADE: ALGUMAS REFLEXÕES CRÍTICAS}

Uma vez apresentada, mesmo que de sobrevoo, uma definição instrumental de interseccionalidade, buscamos nas próximas páginas indicar algumas críticas e pontos de divergência à alternativa interseccional, desenvolvidas por alguns autores. Com efeito, diversos estudiosos afirmam que a teoria interseccional não demonstra uma real eficácia na luta pela defesa dos direitos humanos das populações discriminadas por algum ou por vários sistemas de opressão ou/e hierarquia. Vejamos no que consistem esses argumentos.

\section{Ausência de melhorias das vulnerabilidades}

Segundo esse primeiro conjunto de críticas, a interseccionalidade trataria vulnerabilidades e opressões de forma semelhante, como se cada uma fosse uma via de mão única que, em determinado ponto, cruza outra via e funde-se a uma dessas vias, assim, o entrecruzamento de tais avenidas converge no sentido de discriminar e inferiorizar determinado sujeito. Sendo assim, quanto mais vias, maior a opressão sofrida por aquela pessoa. Seguindo esse pensamento, uma mulher transgênero, 
negra, amazônica, ribeirinha, teria adicionada à sua vivência a soma de todas as suas diferenças identitárias, por exemplo.

Essa visão, segundo Danièle Kergoat (2010), acaba por naturalizar as categorias de análise, sendo a multiplicidade de categorias tratadas de forma interseccional, não levando em consideração relações sociais estabelecidas entre indivíduos em sociedade, sem historicizá-las e desconsiderando as dimensões materiais da dominação. Os sistemas de opressão não são fixos e se encontram inseridos na dinâmica social, a qual está em constante processo de evolução.

A interseccionalidade atua assim, muitas vezes, no sentido de nivelar hierarquias estruturais, tratando as categorias de análise como meras identidades do ser, similares entre si, uma vez que se configuram como opressões. Isso leva à uma compreensão rasa dos sistemas de opressão, limitando a solução do problema ao respeito à diferença, oferecendo muito pouco à luta contra discriminações. O nivelamento das subordinações e discriminação passa assim a desrespeitar a raiz das relações de dominação e a evolução destas, além de seu próprio funcionamento. Então, apesar de a interseccionalidade demonstrar como esses sistemas se suportam e o modo como interagem entre si, apoiando-se entre si, peca ao afirmar serem equiparáveis.

Ademais, a teoria interseccional, baseando-se em experiências individuais acaba por separar grupos que deveriam lutar pelo mesmo objetivo, qual seja, o fim do sistema de hierarquias coloniais, conceito a ser explorado adiante. Com isso, essas disputas passam a ser compreendidas como "luta entre classes" ou "classe contra autoridades". O poder, de forma geral, se beneficia e sustenta a opressão, e essa visão deturpada da opressão das classes auxilia a ocultação da fonte de poder por trás dos sistemas de hierarquia.

Sandew Hira (2016), assim como Kergoat (op cit), afirma ser necessário se compreender a opressão dentro das relações sociais - por exemplo, entre um homem e uma mulher - não existindo apenas uma relação de opressor e oprimido, da mesma forma que essa não é a única relação possível entre um branco e um negro. Ao desconsiderar tal fato, a interseccionalidade é incapaz de promover melhorias nas vulnerabilidades sociais por não compreender o sistema de opressão em toda a sua complexidade e dinâmica. 
Outra crítica diz respeito à análise interseccional considerar, em geral, o binômio gênero e raça, tratando em alguns momentos, apenas, de dimensões como classe social e sexualidade, marginalizando discussões acerca das demais opressões que da sociedade contemporânea ou mesmo invisibilizando-as.

Ao analisar a contribuição feminista e sobre gênero produzida no País, Adriana Piscitelli (2013) registra que, as teorias interseccionais ao viajarem para a terra brasilis, passaram a ser, em larga medida, incorporadas às críticas femininas póscoloniais. Todavia, nesses trabalhos a centralidade dos estudos de gênero deram passagem às abordagens que consideram uma perspectiva política por meio da qual as posições das diferenças nas relações entre homem/mulher/identidade de gênero inclinam-se às percepções que as compreendem como efeitos do racismo, por exemplo. Muito embora, a autora considerar as "noções de interseccionalidade" como "ferramentas férteis no âmbito dos feminismos negros e pós-coloniais", ela registra que a partir dos anos 2000 houve uma "apropriação" descontextualizada em justificativas de políticas públicas no âmbito governamental (PISCITELLI, 2013, p. 389-390). O que pode ser um indicativo de sua má utilização como instrumento de revelação das relações de subalternização e, via de consequência, falha em evidenciar mecanismos de superação das vulnerabilidades.

Obviamente, tratar opressões de cunho racial e de gênero é de fundamental importância. No entanto, compreender a hierarquização que discrimina e subordina sujeitos em suas diferenças sociais vai muito além dessas categorias. A interseccionalidade somente abriria espaço para outras categorias de análise quando essas contribuem para a estruturação das experiências das mulheres negras (CRENSHAW, 1994) e essa prática invisibilizaria outras discussões, ao ponto de impossibilitar, relativamente, debates mais estruturais e profundos a respeito de outros marcadores sociais, como sexualidade, idade, religião, etnia, regionalidade e, com exceção de uma linha alternativa de teóricos interseccionais, nacionalidade. Como indica Hirata (2014, p. 65) ao dialogar com Kergoat, propor uma interseccionalidade variável, que alcance (e, incluímos, supere) opressões de maneira mais abrangente, possivelmente levaria à dissolução da violência das relações sociais, uma vez que a 
reflexão deixaria suas limitações em prol de uma compreensão menos restrita do que se deve analisar no âmbito da opressão e da hierarquia estrutural.

Rejeitar a existência e relevância de determinados marcadores sociais em detrimento de outros é uma atitude equivocada quando se trata de uma teoria que propõe uma discussão voltada à solução de problemas como a opressão e a vulnerabilidade de grupos específicos dentro da sociedade. Isso posto, a interseccionalidade não realizaria integralmente o que se propõe, não contemplando todas as categorias de análise e não atingindo a raiz da questão, ou seja, a teoria permanece na superfície do problema e dificilmente satisfaz os requisitos necessários para moldar soluções passíveis à problemática criada pelo objeto de estudos.

Há, ainda, um outro fator a ser levado em consideração: em que medida utilizarmos como fator predominante para nossas análises categorias trazidas em um contexto de colonização, repressão e dominação não reforça, de alguma maneira, a lógica pela qual elas foram moldadas e estabelecidas? Ao utilizar, sem maiores problematizações, termos historicamente imbuídos de estigmas, corre-se o risco de se reafirmar, mesmo que pela negação, processos de subalternização. Um pensamento heteróclito talvez seja a única forma de se romper com essas amarras epistemológicas, oferecendo um arsenal epistemopolítico viável para um pensamentooutro.

Se a interseccionalidade possui limitantes nesse sentido - sobretudo ao resvalar na reprodução em contextos latino-americanos muitas vezes acrítica de análises feitas no e para o norte epistêmico, ainda que por pensadoras progressistas - talvez a colonialidade nos ofereça uma chave interpretativa apta para pensar esse conjunto de questões? Dito de outra maneira, as zonas obscuras e fissuras causadas pela colonização, em especial em contextos de ameaças a Direitos e sujeitos-outros, podem ser alcançadas pela aplicação de preceitos decoloniais, dados os limites da teoria interseccional, ao menos como essa se afigura neste momento? A ver.

\section{TRAZENDO O COLONIAL PARA A CONVERSA SOBRE DIREITOS HUMANOS}

Antes de mais nada, vale a pena estabelecermos aqui, como corolário, que uma hierarquia estrutural baseada em múltiplos sistemas de opressão que se entrecortam, existe. A questão passa a ser como desvelá-la a fim de enfrentá-la, 
apropriadamente. Se, como afirmamos acima, há o risco de se reforçar essas categorias de exclusão e subalternização ao se utilizá-las de forma inadvertida, nossa hipótese passa a ser de que uma discussão que parta da problematização de suas origens como forma de compreender suas estruturas é, literalmente, essencial.

A "descoberta" das Américas interligou os seres humanos dos dois hemisférios inaugurando o sistema-mundo comercialmente globalizado. Desde então, articulou-se saberes para consolidar e exportar para o Novo Mundo a ideação civilizatória europeia ocidental. Nesse sentido, a modernidade colonial é entendida como o mais avançado sistema cultural, econômico e político em relação aos mais diversos arranjos sociais globais. O colonialismo moderno pode ser entendido como a constituição histórica dos territórios coloniais especificamente forjados pelos impérios ocidentais por meio de representações materiais e simbólicas que o sustenta (MALDONADO-TORRES, 2019).

Partamos de Fernanda Bragato (2016), ao apontar como o processo de colonização das Américas baseou-se um discurso desumanizante, não apenas justificando e legitimando as atrocidades cometidas contra indígenas e negros, como também construindo uma série de conceitos cujos efeitos podem ser notados na sociedade. Negros, indígenas, não-cristãos, homossexuais, mulheres, transexuais, transgêneros, travestis, ribeirinhos amazônicos, campesinos e sem-terra, refugiados haitianos e venezuelanos - que recentemente empreenderam diáspora causando impactos sociais a evidenciar a seletividade dos direitos humanos no Acre e em Roraima, respectivamente -, entre outros, são submetidos a discriminações baseadas em um sistema hierárquico em cujas raízes estão relações coloniais e o próprio conceito de modernidade. A colonialidade seria, para pensadores latino-americanos (como Quijano, Mignolo, Castro-Gómez, entre outros, como veremos) a continuidade dessas hierarquias mesmo após findo o colonialismo enquanto instituição política. Dessa forma, pensamos que uma crítica radical dessas hierarquias passe, necessariamente, por saberes e subjetividades que se posicionem ontologicamente para além das categorizações postas pelas relações coloniais. Chamar os feminismos latino-indígenas, ou os queeres afro-latinos, por exemplo, de visadas interseccionais é, em larga medida, limitar seu caráter de crítica radical a um feixe de relações de poder em cuja base estão outras questões, como representatividade, democracia, poder, território, emancipação... Talvez a mesma crítica possa ser feita, quem sabe, à 
própria noção de "colonialidade"... Como situar, por exemplo, alguém da potência de Gloria Anzaldúa e de alguns de seus escritos: pós-colonial, queer, interseccional?

Em se tratando de Brasil, especificamente, Carolina Maria de Jesus (Quarto de Despejo), Darcy Ribeiro (Aos trancos e barrancos), Roberto Gomes (A crítica da razão tupiniquim), Manoel Bomfim (América Latina: males de origem), para citarmos apenas alguns, estão situados em algum lugar entre a crítica colonial e a interseccionalidade; ou ao buscar encaixá-los em confortáveis escaninhos acadêmicos, nos omitimos do desafio de pensarmos uma epistéme-outra? A multirrealidade brasileira, se não pensada de e para lugares de enunciação marginais (postos que à margem) caboclos, sertanejos, ribeirinhos, favelados, retirantes, refugiados... - das grandes chaves interpretativas tornam-se meros espelhos do pensamento crítico euronorcêntrico. Ao invisibilizá-los retira-se-Ihes qualquer potência de humanidade, posto não se enquadrarem nos preceitos modernos, liberais e cristãos de "humanos" (justificativa, inclusive, para a usurpação de seus direitos, tema deste dossiê).

A construção do próprio conceito de humanidade, aliás, deu-se com base em dois preceitos principais, os quais serviram de parâmetro para se julgar quem seria legítimo titular de direitos e detentor do poder; e quem seria segregado oficialmente e socialmente inferiorizado dentro das relações interpessoais.

O primeiro desses preceitos é a racionalidade, diretamente relacionada à capacidade de compreensão e linguagem culta e científica. Nesse contexto, por racionalidade deve-se entender o pensar/agir de acordo com os ideais, cultura, religião e raciocínio político e científico dos homens europeus, cristãos, brancos, modernos, liberais...

Às mulheres, por exemplo, eram atribuídas características como instabilidade, emoções, paixões, graça, loucura e atratividade, de forma que estas não eram consideradas aptas a desenvolver uma racionalidade semelhante à dos homens. Essa visão infantilizada do sexo feminino, retira[va] a autonomia das mulheres (BRAGATO, 2016) e marginaliza[va] seus pensamentos, opiniões e ambições como ser humano. Pelo uso desses argumentos, as mulheres foram - e são - afastadas da vida política, impedidas de estudar e manter fontes de renda próprias, consideradas propriedade de seus pais e maridos e sofreram opressões de cunho físico (o uso de espartilhos e determinadas roupas, agressões físicas), psicológico (inferiorização da feminilidade) e sexual (agressões sexuais, submissão ao cônjuge). 
Os indígenas e negros, por sua vez, eram considerados selvagens, bárbaros e bestiais. A cultura desses povos se opunha sobremaneira àquela trazida pelos colonizadores europeus, sendo esse ponto crucial no momento de hierarquizar a relação colonizadores - colonizados.

Suas cosmologias e ontologias foram percebidas pelos europeus como ausência de racionalidade, havendo eles sofrido também com a supressão de suas religiosidades e culturas, uma vez que a noção de humanidade tomada de empréstimo aos valores eurocêntricos se sobrepunha a qualquer ideia divergente.

Quanto às mulheres colonizadas, María Lugones (2014) aponta como a essência da missão civilizatória não cedia espaço para a separação dos colonizados de acordo com o gênero e a ideia de emprestar-lhes a identidade homem/mulher era compreendê-los como seres. Entretanto, mesmo que a gendrificação dicotomizada dos colonizados fosse contrária os anseios desumanizantes dos colonos, aqueles foram avaliados de acordo com o gênero. Assim sendo, a mulher colonizada, a princípio, não existe, por ter sido colonizada e escravizada como ser e não como gênero. Essa autora propõe, assim, uma discussão feminista decolonial, por meio da qual compreenda-se a colonialidade de gênero por meio da perspectiva da diferença colonial e somente então, afirma ser possível tratar sobre a libertação feminista de mulheres de cor.

Nessa perspectiva, María Lugones (2014) enfatiza a importância de problematizar a articulação de diversos vetores de tensões que se fazem presentes na ferida colonial. Segundo Walter Mignolo (2017), a diferença/ferida colonial é o espaço onde a colonialidade do poder é exercida, e engendra uma resposta ao discurso e aos posicionamentos hegemônicos aos quais revelam uma perspectiva subalterna/fraturada, que por sua vez tem o condão de transcender a própria diferença colonial a partir do exercício do conhecimento gerado desde um novo terreno epistemológico e peculiar.

O segundo requisito aplicado ao conceito ocidental de humanidade foi 0 conhecimento, diretamente ligado ao saber e à história de evolução e desenvolvimento de determinado grupo. Para atender a esse requisito, a história daquele povo deveria organizar-se de forma semelhante à experiência da Europa, com a evolução de conceitos e produção de conhecimento nas áreas da economia, estado, sociedade, mercado. Fernanda Bragato (2016), novamente, aponta que a 
validade exclusiva do modelo eurocêntrico ignora[va] outras formas de conhecimento e desconsidera[va] a possibilidade de coexistência com as perspectivas advindas de outros meios.

Essa negação e marginalização das fontes de conhecimento dos povos conquistados foi e é utilizada não apenas para desumanizar, mas também para disciplinar. Segundo Nelson Maldonado-Torres (2019), a violência como instrumento de autoridade foi empreendida em múltiplos sentidos nos territórios coloniais instaurando um estado de guerra sem armistício possível, continuamente desferida contra os colonizados e seus descendentes. Corolário disso, foi o recrudescimento de um maniqueísmo simplista em que o colonizador seria a encarnação da bondade e os colonizados a representação e destinatários de um conjunto de qualidades negativas. Essa "naturalização" da violência direcionada foi essencializada na condição de colonizado a ponto de embotar as suas subjetividades, forçando-os a mimetizar pensamentos e comportamentos, quando não arregimentando colonizados para servir aos colonos a fim de consumar e/ou justificar violações.

$\mathrm{Na}$ modernidade, já se reconhecia a existência de direitos inalienáveis decorrentes da natureza humana. Entretanto, o conceito de humanidade baseada em modelos euronorcêntricos de racionalidade e conhecimento serviu para separar aqueles que são humanos daqueles que não o são plenamente e, por isso, não são dignos de direitos. Sob esse argumento, a sociedade europeia justificou a violação de direitos humanos daqueles que não eram reconhecidos como tais, legitimando, em nome de Deus e, posteriormente, da raça, do progresso, do desenvolvimento ..., o extermínio, a escravização e os maus-tratos contra determinados grupos.

Com isso, nota-se que o colonialismo estabeleceu um padrão do que é ser plenamente humano e digno de direitos e esse conceito permanece exercendo influência nas relações sociais contemporâneas. Como dito anteriormente, o colonialismo terminou, entretanto, a colonialidade continua presente, definindo elementos culturais, de mercado de trabalho, de produção de conhecimento e influenciando nas relações sociais, sociabilidades, afetos e subjetividades.

Nesse sentido, é particularmente interessante a compreensão da extensão temporal dos efeitos do colonialismo não como um passado distante, mas atual, na emergência dos acontecimentos. Assim, "[...] essa transformação do tempo em si, de um tempo histórico-cronológico para o que parece ser uma forma de temporalidade 
anacrônica por meio da qual grupos expostos a lógicas e conflitos que são considerados não mais existentes [...]" é questão central para o desenvolvimento de estratégias de superação das subalternidades/vulnerabilidades. A perspectiva crítica à colonialidade se preocupa em pôr em xeque o "senso comum" e as conjecturas científicas relacionadas aos pilares de sustentação da modernidade ocidental tais como tempo, espaço, saberes, corporalidades e subjetividades com o objetivo de superá-los. Noutro giro, isso implica, para além da desmistificação da supremacia ocidental, uma concepção de reorganização do sistema-mundo onde as mais diversas compreensões de "mundo" possam coexistir (MALDONDO-TORRES, 2019, p. 28).

A colonialidade enseja a violação seletiva de direitos humanos, relacionandose diretamente à desumanização da pessoa. Racismos, machismos, misoginia, xenofobia, LGBTQlfobia, entre outros, são exemplos de manutenção de sistemas de superioridade baseadas pressupostos que nos acompanham desde o nascimento da América: ainda assim, relacioná-los à colonialidade não nos permite encerrá-los em grandes narrativas generalizantes, bem como compreendê-los à luz da interseccionalidade não pode significar descartar os múltiplos feixes de opressão nesses processos.

Um ponto a ser destacado, então, não é a existência de subalternizações diversas intercruzando-se e convergindo de forma pontual, mas a presença e manutenção de lugares de enunciação desde os quais problematiza-se a própria aplicabilidade de direitos humanos básicos, com fundamento em características percebidas como inferiores, posto que não hegemônicas. A lógica, infelizmente, cada vez mais presente em conversas cotidianas e falas de grupos políticos, de que "direitos humanos são para humanos direitos" nos deve causar não apenas indignação, mas, também, uma indagação: um humano "não direito", é um humano? Nesse sentido, o que é "ser direito"? Tem-se, assim, uma sinonímia entre humanidade, caráter ("cidadão de bem") e adequação às normas e aos processos de normalização modernos, brancos, cristãos, liberais, cisgêneros, héteros, masculinos... ser humano é enquadrar-se nesse combo. Não se trata apenas de reconhecer esses ingredientes, mas de problematizá-los estruturalmente, sem perder o caráter de especificidade dos elementos às margens desse sistema.

A colonialidade parece complementar o olhar interseccional, ao subverter essa ordem estrutural moderno/colonial ao revelar outras línguas, religiões, conceitos 
políticos e econômicos, os quais, a despeito da insistente sede de apagamento imperial, resistiram (MIGNOLO, 2008). Tais discriminações, em essência, implicam que quanto mais distante o sujeito estiver do padrão euronorcêntrico, mais justificada é a violação de seus direitos. Ao trazer à tona a consciência mestiça de Rodolfo Kusch e de Glória Anzaldúa, traduzida como chave interpretativa para a "diversidade" latinoamericana, como uma forma de realocar a racionalidade e de revelar os aspectos regionais de consciência desqualificada porque lida como universal (colonizada) e não pluriversal (nativa), permite-se que vejamos claramente qual o projeto de poder a ser combatido prima facie - ao nosso ver uma vantagem sobre o olhar interseccional mais frequente.

Quando Glória Anzaldúa exercita por intermédio de questionamentos o que seria sua subjetividade (mulher, lésbica, mestiça, proletária) e o que deles se depreende, expressa o desafio de superar a lógica taxonômica euronorcêntrica praticando o pensamento fronteiriço, mas também acessando o lócus fraturado a partir da diferença colonial. A ação insurgente contra os padrões que nos situam no chão da existência cotidiana, um terreno epistemopolítico que enceta, ao mesmo tempo, o tensionamento de múltiplas estratégias de agenciamento e reapropriação da subjetividade. Esse "ser-sendo" relacional é a consequência primeira de habitar a fratura, a segunda são as transformações advindas das problematizações (LUGONES, 2014), noutras, palavras é ir além do além, para depois das performatividades óbvias do imaginário colonial-capitalístico num des-fazer-se e/ou a re-fazer-se multivetorial continuamente consciente a desafiar a normatividade social e renovar o processo de subjetificação relacional a partir da resistência às pressões que negam a complexidade de nossa existência.

Latinidades (afro e indígenas, inclusive) "naturalmente" forçadas e forjadas de fora para dentro de dentro para fora, violentamente expropriadas do ser, do estar e do pensar, trazem para si a enunciação própria emancipatória e desobediente como sua maior riqueza. Expropriados de si mesmos agora se defrontam com seu próprio ser, mas antes devem reconhecer as diferenças que nos une como imanentes à sua/nossa condição periférica. É crucial, assim, a transição da política de identidade para a identidade em política, romper as barreiras das identidades fraturadas e das comunidades marginalizadas, fazendo-se imperioso superar não apenas a busca pelo 
mero reconhecimento da ululante humanidade, mas perseguindo a legitimação da inserção, comprometimento e engajamento para além dos muros da sociedade civil.

Em larga medida, a teoria da interseccionalidade revela apenas algumas facetas da matriz racializada de opressão, todavia não oferece, de modo geral, ruptura antissistêmica. Talvez faça algum sentido no contexto do Norte-Global, mas não abaixo deste lado do muro (simbólico, ainda) trumpista. Deste lado, os efeitos da colonialidade operam hierarquizando o ser, o estar e o saber, com mais força que nunca.

\section{ALGUMAS CONSIDERAÇÕES FINAIS}

Sim, as diversas abordagens interseccionais jogaram luzes para vivências não problematizadas pela academia e sociedade. Essa contribuição para a mise-en-scène fez borbulhar e germinar estudos sociológicos relevantes para a compreensão da tecnologia da opressão contemporânea. Pensar a hierarquização do poder por meio das lentes de uma realidade tripartite, qual seja, raça/gênero/classe faz com que exercitemos a racionalidade lógica necessária para a observância das micro relações de poder que operam demasiadamente presentes no cotidiano e, por isso mesmo passam despercebidas aos olhares incautos. Todavia, tais abordagens não ajudam, de modo geral, na compreensão dos mecanismos que forjaram essas relações hierárquicas fazendo com que desviemos o olhar da face estrutural por trás da distribuição de poderes e direitos que, historicamente, nos formaram.

Retomando a ponderação inicial deste texto, a interseccionalidade é uma opção decolonial? Como desdobramento, ela faz algum sentido para a elucidação dos dilemas sociais e de violações de direitos humanos na América Latina? À primeira pergunta respondemos com um retumbante "não". Em nosso entendimento, as explicações mais usuais desde o olhar interseccional não são radicais o suficiente, do ponto de vista epistêmico. Há, sim, um olhar desde as fissuras do sistema colonial, mas sem romper com as estruturas desse sistema. Falta o olhar da fronteira, uma perspectiva que provoque - não apenas invoque - e enfrente o feixe de relações estruturais a partir das quais o hegemônico torna-se hegemônico. Nada de desver, desouvir, desaprender, dessentir, depensar, ressubjetivar, desespistemologizar para epistemopolitizar... nada de propor animus desprovido de grilhões coloniais. Sem 
ruptura radical. A interseccionalidade mostra o espelho para Medusa, sem Ihe cortar a cabeça.

A colonialidade do poder, por outro lado, disciplinou a diferença colonial e continua a fazê-lo, inserida e construída neste palco está a América Latina, periférica e coadjuvante de sua própria história e (r)existência: deslocada, descentrada e subalternizada. Trata-se de um rompimento com as articulações e forças, vozes, escutadas ou apagadas, de memórias acachapadas ou fraturadas, ou mesmo como ensina Mignolo (2005, p. 76) romper com as "[...] histórias contadas de um só lado, que suprimiram outras memórias e de histórias que se contaram e se contam levandose em conta a duplicidade de consciência que a consciência colonial gera [...]" é premente.

Isso não significa, contudo, uma adesão irrestrita e acrítica à chave decolonial. Fato é que várias tem sido as contribuições do pensamento decolonial ao Direito no Brasil (o Moitará, grupo de pesquisas em Direito na UnB; discussões no âmbito do LAEPI/ELA, também na UnB, escritos de autoras como Rita Segato, Ella Castilho e Sandra Nascimento, são bons exemplos disso) e, consequentemente, tem servido de base a uma discussão mais consolidada sobre Direitos Humanos fora das perspectivas positivadas ou liberais do Direito e do Estado. Pensamos que sua superutilização pode, sim, esvaziar seu potencial de crítica e ainda estamos no nível da reprodução, pura e simples, de conceitos decoloniais à realidade social do país. Agindo assim, nos deixamos colonizar por mais uma teoria crítica - como o póscolonial, estudos culturais, interseccionalidade etc. Uma guinada decolonial pressupõe, sobretudo, um olhar da realidade social para a teoria, não o contrário.

Não se trata, como muitos tem feito - a etiqueta acadêmica nos impede de apontar nomes - de analisar o feminismo negro ou o movimento indígena a partir da colonialidade, mas de compreender esses espaços como lugares de enunciação epistemopolíticos. Trata-se de ouvi-los, mais do que de interpretá-los. Trata-se de incorporá-los, mais do que de objetivá-los.

Dessa maneira, a discussão sobre Direitos Humanos e povos das Américas passa a ser, também, uma reflexão sobre povos nas Américas. Compartilharmos desse continente não é um mero detalhe, e qualquer análise ou enfrentamento sobre o tema, em nosso continente, deve fazer frente à realidade social da América profunda, de sua história e de seus atores, sem diluir suas diferenças em categorias 
colonizadas, tampouco obscurecê-las em macro categorias acadêmicas ou chaves interpretativas totalizantes ou na moda.

\section{REFERÊNCIAS BIBLIOGRÁFICAS}

ANZALDÚA, Gloria. Speaking in tongues: a letter to 3rd world women writers. In: MORAGA, Cherrie; ANZALDÚA, Gloria. This bridge called my back: writings by radical women of color. Watertown: Persephone Press. p. 165-174. 1981

ANZALDÚA, Gloria. Borderlands/La frontera: the new mestiza. São Francisco: Aunt Lute Books, 2007.

BRAGATO, Fernanda. Discursos desumanizantes e violação seletiva de direitos humanos sob a lógica da colonialidade. Revista Quaestio luris, v. 9, n. 4, p. 18061823, 2016.

BRAH, Avtar. Diferença, diversidade e diferenciação. Cadernos Pagu, n. 26, jan.jun., p. 329-376, 2006.

CRENSHAW, Kimberlé. A intersecionalidade na discriminação de raça e gênero. 2004. Disponível em: <http://www.acaoeducativa.org.br/fdh/wp-

content/uploads/2012/09/ Kimberle-Crenshaw.pdf> Acessado em 04 de junho de 2020.

CRENSHAW, Kimberlé. Why intersectionality can't wait. 2015. Disponível em: < https://www.washingtonpost.com/news/in-theory/wp/2015/09/24/why-intersectionality-cantwait/> Acessado em 04 de junho de 2020.

GONZALEZ, Lélia. Racismo e sexismo na cultura brasileira. Revista Ciências Sociais Hoje, Anpocs, p.223-244, 1984.

GONZALEZ, Lélia. A categoria político-cultural de amefricanidade. Tempo Brasileiro, n. ${ }^{\circ}$ 92/93, jan.-jun., p. 69-82,1988.

HIRA, Sandew. A decolonial critique of intersectionality. 2016. Disponível em: < https://din.today/a-decolonial-critique-of-intersectionality/> Acessado em 02 de junho de 2020.

HIRATA, Helena. Gênero, classe e raça: interseccionalidade e consubstancialidade das relações sociais. Revista Tempo Social, v. 26, n. 1, p. 61-73, 2014.

KERGOAT, Danièle. Dinâmica e consubstancialidade das relações sociais. Novos Estudos Cebrap, v. 29, n.1, p. 93-103, 2010 
KUHN, Thomas. A estrutura das revoluções científicas. São Paulo: Editora

Perspectiva S.A, 1997.

LUGONES, María. Rumo a um feminismo descolonial. Revista Estudos Feminista, v. 22, n. 3, p. 935-952, 2014.

MALDONADO-TORRES, Nelson. Analítica da colonialidade e da decolonialidade: algumas dimensões básicas. In: BERNADINO-COSTA, Joaze; MALDONADOTORRES, Nelson; GROSFOGUEL, Ramón (orgs.). Decolonialidade e pensamento afrodiaspórico. Belo Horizonte: Autêntica Editora, 2019, p. 27-53.

McKLINTOCK, Anne. Imperial leather: race, gender and sexuality in the colonial contest. New York: Routledge, 1995.

MIGNOLO, Walter. A colonialidade de cabo a rabo: o hemisfério ocidental no horizonte conceitual da modernidade. In: LANDER, Edgardo (org.). A colonialidade do saber: eurocentrismo e ciências sociais. Buenos Aires: Clacso, 2005, p. 71-103. MIGNOLO, Walter. Desobediência epistêmica: a opção descolonial e o significado de identidade em política. Cadernos de Letras da UFF. Dossiê Literatura, língua e identidade, ํo 34, p. 287-324, 2008.

MIGNOLO, Walter. Colonialidade: o lado mais escuro da modernidade. Revista Brasileira de Ciências Sociais, vol. 32, n. 94, p. 1-18, 2017.

PISCITELLI, Adriana. Interseccionalidade, categorias de articulação e experiências de migrantes brasileiras. Revista Sociedade e Cultura, v. 11, n. 2, 2008.

PISCITELLI, Adriana. Atravessando fronteiras: teorias pós-coloniais e leituras antropológicas sobre feminismos, gênero e mercados do sexo no Brasil. Contemporânea, v. 3, n. 2, p. 377-404, 2013.

PRINS, Baukje. Narrative accounts of origin: a blind spot of the intersectional approach? European Journal of Women's Studies, v. 13, n. 3, p. 277-290, 2006. Disponível em: <https://hal.archives-ouvertes.fr/hal-00571279/document> Acessado em 15 de agosto de 2020.

RIOS, Flávia; RATTS, Alex. A perspectiva interseccional de Léila Gonzales. In: PINTO, Ana Flávia Magalhães; CHALHOUB, Sidney (orgs.) Pensadores Negrospensadoras negras: Brasil, séculos XIX e XX. Cruz das Almas, EDUFRB; Belo Horizonte: Traço Fino, 2016, p. 387-403. 